\title{
Effect of topical local anaesthesia on injection pain associated with administration of sterile water injections - a randomized controlled trial
}

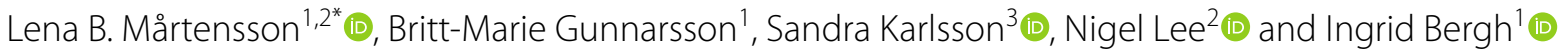

\begin{abstract}
Background: Sterile water injections can provide effective pain relief during childbirth, particularly for low back pain related to childbirth. However, the pain associated administering the injections can negatively impact women's impressions of the procedure. It may discourage women from considering repeat doses despite the quality of analgesia experienced. Determining strategies to reduce the pain related to the administration of sterile water injections would improve the acceptability of the technique. Therefore, the aim of this study was to evaluate the effect of topical local anesthesia on the pain associated with administration of sterile water injections.
\end{abstract}

Methods: The study was designed as a multi-arm single-blind, randomized, controlled trial and 120 female healthy students were randomly divided according to one of four groups. The Intervention group received sterile water injections with topical local anesthesia. Control group 1 received sterile water injections without topical local anesthesia, control group 2 received injections of isotonic saline $0.9 \%$ with topical local anesthesia and control group 3 received injections of isotonic saline $0.9 \%$ without topical local anesthesia. Pain Immediately after the injections and subsidence in pain were recorded using a visual analogue scale. Sensations in the injection area were reported 15 min and the day after the injections.

Results: The main finding of this study was that local anesthesia with EMLA ${ }^{\circledR}$ reduces the pain associated with the administration of intracutaneous sterile water injections. There was a significant difference in the self-assessed pain score immediately following the injections between the control $(73.3 \mathrm{~mm})$ and intervention groups $(50.0 \mathrm{~mm})$, $p=0.001$. No adverse side effects were reported.

Conclusion: Local anesthesia with EMLA ${ }^{\circledR}$ reduces the pain associated with intracutaneous administration of sterile water injections.

Trial registration: The study was registered 08/07/2014 at ClinicalTrials.gov Identifier: NCT02213185.

Keywords: Pain, Pain relief, Sterile water injections, Randomized controlled trial, Childbirth

*Correspondence: lena.martensson@his.se

${ }^{1}$ School of Health Sciences, University of Skövde, P.O. Box 408, SE-541 28 Skövde, Sweden

Full list of author information is available at the end of the article

\section{Background}

Most women in childbirth experience intense pain. This kind of pain can affect the women's experience of childbirth negatively for up to 1 year postnatally [1]. The pain may even result in symptoms of post-traumatic stress [2]. Safe and effective pain relief should therefore be available 
for all women. However, many women are reluctant or hesitant to accept pharmacological pain relief out of concern for possible adverse side effects on themselves or their unborn baby [3]. Since the mid-1980s, sterile water injections (SWI) have been used to alleviate low back pain during childbirth [4]. In addition to treatment for childbirth pain, SWI has been used to relieve chronic neck pain, renal colic [5] and ureterolithiasis during pregnancy [6].

Along with several smaller studies, a large doubleblind, randomized controlled trial successfully demonstrated that SWI could provide effectively relief for low back pain during childbirth [7]. Clinical guidelines for the use of the procedure have earlier been published [4]. Previously it has been reported that the pain associated with administering the injections can negatively impact women's experiences $[8,9]$. It has also been reported that women rated the injection pain as more painful than labor contractions [10]. Further, midwives have reported reluctance to recommend this treatment due to the pain inflicted during the administration of the injections [11].

SWI is a simple and inexpensive method involving the injection of small volumes of sterile water intracutaneously $(0.1 \mathrm{ml})$ or subcutaneously $(0.5 \mathrm{ml})$ at the site/s at which the woman perceives pain, Fig. 1 . The most common technique entails the administration of four injections, but three studies demonstrated a good effect after just one injection [12-14]. Whether pain relief is influenced by the number of injections or the volume of sterile water per injection has been discussed $[15,16]$. However, Lee et al. [14] found that four injections resulted in better pain relief effect than one injection. Pain relief usually occurs within a few minutes and can be repeated if needed $[17,18]$. The only observed disadvantage of SWI is the injection pain. The pain can be described as similar

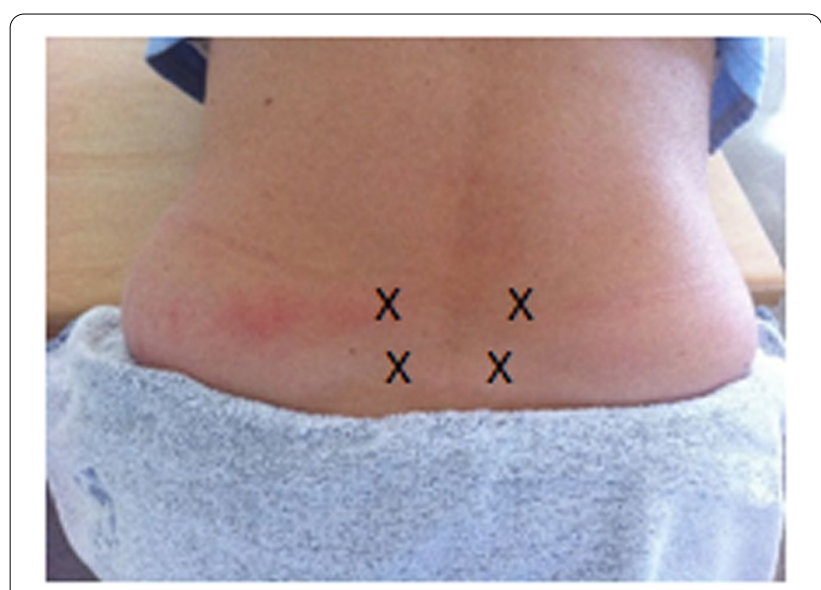

Fig. 1 Locations of the injections to a bee or wasp sting, with a duration of approximately 20-30 s [4]. In an earlier cross-over study including 100 non-pregnant healthy women reported that the injection pain was considerably reduced if the injections were administered subcutaneously using a somewhat more substantial volume of sterile water [19].

Moreover, subcutaneously SWI in laboring women seems to give a similar pain relief effect compared to intracutaneous injections [20]. However, in clinical practice, women still find subcutaneous injections painful, especially when receiving multiple injections. It is therefore relevant to question if local anesthetic can reduce the pain related to the injections. Byrn et al. [21] advised against administering local anesthetic before SWI but provided no evidence or physiological basis to support this recommendation. In a later study, Iwama et al. [22] showed excellent relief from myofascial pain when the local anesthetic was combined with sterile water or isotonic saline. However, the trial did not include a comparative non-anesthetic control group. The anti-nociceptive mechanisms of SWI are not fully understood, but some theories are found in the literature. One is the gate control theory [23], another is descending pain relief system [24] and finally, the diffuse noxious inhibitory control (DNIC) [25]. Moreover, not much is known about how fluid is absorbed in the tissue during intradermal injections, and there are no known in depth-studies showing flux characteristics in the tissue [26].

The pain associated with administering water injections is now arguably the main deterrent to more widespread acceptability and use of this method. A small number of studies suggest the use of local anesthetics may be of use in this regard. However, the inclusion of injectable drugs, such as lidocaine, also involves some injection discomfort. Furthermore, no studies have yet tested this approach against a placebo control. The use of topical anesthetics may avoid the inherent injection pain of local anesthetics providing a suitable alternative. Therefore, this study aimed to evaluate the effect of topical local anesthesia on pain associated with the administration of sterile water injections.

\section{Methods \\ Aim}

The aim of this study was to evaluate the effect of topical local anesthesia on the pain associated with the administration of sterile water injections.

\section{Study design}

The study was designed as a single-blind, randomized, controlled trial with four arms following the CONSORT guidelines [27]. Data collection took place from September 2014 to December 2019. 


\section{Participants and recruitment}

As there is some evidence to suggest a gender difference in the perception of pain, female participants were used to more closely reflect the possible effect of the intervention in laboring women [28]. A previous study with a similar design [19] also showed that it is possible to recruit students even if the trial could involve an experience of pain during the administration of injections. Recruitment of voluntary female students took place at one University in the Western part of Sweden.

Information about the study was first given on the student noticeboards. However, this approach was not practical, and only a small number of students responded. Therefore, we changed to more targeted information. Nursing and midwifery students received information about the study during an appropriate course introduction during their first week at the University. Interested students were requested to put their names on a list. They were also informed that the registration was not binding. The students were then contacted, and if they still were interested in participating, a time for scheduling the injections was decided. It was not possible to know how many of the nursing and midwifery students fulfilled inclusion criteria. Therefore, it is impossible to identify how many students were eligible to participate in the study. Oral and written information was once again given just before the injections were given. A further check was made to ensure that all inclusion criteria were met. The exclusion criteria were based on conditions that possibly could have an impact on the experience of pain $[29,30]$.

\section{Criteria for inclusion}

- Female

- Age 18-45 years

- Substantially healthy (self-reported)

- Sufficient knowledge of the Swedish language to understand written and oral instructions.

\section{Criteria for exclusion}

- Pregnancy

- Hypersensitivity to Lidocaine and Prilocaine

- Previous experience of SWI

- Ongoing pain

- Use of medication for depression, pain, or sleeping disorder $24 \mathrm{~h}$ before the experiment

- Smoking, snuffing (a type of tobacco that is kept in the mouth), physical activity, and intake of caffeinated beverages (coffee, tea, or energy drink (e.g., Red Bull)) $2 \mathrm{~h}$ before the experiment.

\section{Randomization and procedure}

A randomization protocol was created by independent statisticians using random number generator software. Information about the treatment group, to which the women had been randomized, was kept in prepared non-transparent envelopes containing study protocol and questionnaire.

\section{Primary outcome}

- Pain immediately after administration of the injections.

\section{Secondary outcomes}

- Subsidence in pain

- Sensations in the injection area were reported $15 \mathrm{~min}$ after injections

- Sensations in the injection area were reported the day after injections

For many years, topical preparations such as EMLA ${ }^{\circledR}$ have been routinely used in Swedish hospitals as a local anesthetic to relieve the pain associated with various forms of injections. An EMLA ${ }^{\circledR}$ patch consists of a mixture of $25 \mathrm{mg}$ lidocaine and $25 \mathrm{mg}$ prilocaine. EMLA ${ }^{\circledR}$ usually provides appropriate analgesia within 1 to $2 \mathrm{~h}$, and the effect lasts up to $2 \mathrm{~h}$ after removal of the patch [31]. An EMLA ${ }^{\circledR}$ patch provides skin analgesia corresponding to a depth of $2.9 \mathrm{~mm}$ after $60 \mathrm{~min}$ of application and $4.5 \mathrm{~mm}$ after $120 \mathrm{~min}$ [32], which means that, in this particular situation, intracutaneous injection was preferable to subcutaneous. A patch without anesthetics was used as placebo in control groups 2 and 3. Isotonic saline $(\mathrm{NaCl} 0.9 \%)$ was used since the percentage of salt in isotonic saline is similar to in the body. The latter means that the isotonic saline does not cause the same degree of osmotic irritation as sterile water, which is saltfree [19]. However, the pain related to the needling of the skin is the same irrespective of the fluid thereafter injected. After providing informed consent, participants meeting the inclusion criteria was randomized into one of four groups:

\section{Intervention group (EMLA SWI)}

Four EMLA ${ }^{\circledR}$ patches were applied to the skin of the lower back (Michaelis Rhomboid; Fig. 1). After $1.5 \mathrm{~h}$, the patches were removed, and one injection of sterile water $(0.1 \mathrm{ml})$ was given intracutaneously at each of the patch locations, in a total of four injections.

\section{Control group 1 (placebo SWI)}

Four placebo patches were applied to the skin of the lower back (Michaelis Rhomboid; Fig. 1). After $1.5 \mathrm{~h}$, the 
patches were removed, and one injection of sterile water $(0.1 \mathrm{ml})$ was given intracutaneously at each of the patch locations, in a total of four injections.

\section{Control group 2 (EMLA NaCl 0.9\%)}

Four EMLA ${ }^{\circledR}$ patches were applied to the skin of the lower back (Michaelis Rhomboid; Fig. 1). After $1.5 \mathrm{~h}$, the patches were removed, and one injection of isotonic saline $(\mathrm{NaCl}, 0.9 \%)(0.1 \mathrm{ml})$ was given intracutaneously at each of the patch locations, in a total of four injections.

\section{Control group 3 (placebo $\mathrm{NaCl}$ 0.9\%)}

Four placebo patches were applied to the skin of the lower back (Michaelis Rhomboid; Fig. 1). After 1.5h, the patches were removed, and one injection of isotonic saline $(\mathrm{NaCl}, 0.9 \%)(0.1 \mathrm{ml})$ was given intracutaneously at each of the patch locations, in a total of four injections.

\section{Instruments}

\section{Visual analogue scale}

A horizontal Visual Analogue Scale (VAS) was used to assess the primary outcome, the perceived pain related to the injections. VAS is a $100-\mathrm{mm}$-long, ungraded vertical or horizontal line with the suggested endpoints 'no pain' (left) and 'worst imaginable pain' (right) [33]. The VAS is sensitive to pain intensity [34-36], and most individuals have no difficulties using it [35,37]. VAS scores can also be divided into three main categories. i.e. mild pain $(\leq 30 \mathrm{~mm})$, moderate pain $(31-70 \mathrm{~mm})$ and severe pain $(>70 \mathrm{~mm})$ [38]. The participant marked an appropriate point on the horizontal scale with a vertical line.

\section{Case report form}

The study protocol consisted of ten pages, one for each time-point of the measurements point (immediately after the injections, $30 \mathrm{~s}$ after the injections, and then after 1 , $2,3,4,5,10$ and $15 \mathrm{~min}$ ). The participants could not see their previous care which might influence the current score. In the end of the form there was an open-ended question regarding experienced sensation in the injection area.

\section{Questionnaire}

The questionnaire contained questions about age, parity, marital status, education, other occupation, menstrual cycle patterns and date of last menstrual period.

\section{Data collection}

All participants were registered by date, name and date of birth in a logbook. The code on the envelope, study protocol and questionnaire were also registered. No names or date of birth was recorded in the study protocols or questionnaires, only the code, which makes it possible to identify the participants in the logbook. At the time of allocation, the person responsible for data collection selected the envelope with the lowest number. In the envelope there was information about which patches and injections the participant were to receive. The participants were unaware of the group they were randomized to. The logbook was kept in a locked cupboard, separate from study protocols and questionnaires.

After randomization, the participants scored any current pain they were experiencing on a VAS to exclude those with pre-existing or 'ongoing pain'. After that, four EMLA $^{\circledR}$ patches were applied to the skin of the low back (Michaelis Rhomboid, Fig. 1) in the intervention group and the control group 2. In the control group, 1 and 3, four placebo patches were applied in the same way. The women were then requested to complete the questionnaire. After $1.5 \mathrm{~h}$, the patches were removed, and one injection of $0.1 \mathrm{ml}$ sterile water (in the intervention group and the control group 1) or $0.1 \mathrm{ml} \mathrm{NaCl}, 0.9 \%$ (in the control group 2 and 3) were given. All injections were given intracutaneously at each location where the patches were placed. In total, four injections were given to all women. Two of the researchers administering two injections each at the same time. All injections were given via a $1 \mathrm{ml}$ Mantoux plastic syringe and a thin needle (B. Braun Omnifix; diameter: $0.40 \mathrm{~mm}$, length: $20 \mathrm{~mm}$ ). Immediately after the injections had been given (approx. 1-3s), the participants were asked to score the pain related to the injections on a VAS. The perceived pain in the injection area was repeated $30 \mathrm{~s}$ after the injections, and then after 1, 2, 3, 4, 5, 10 and $15 \mathrm{~min}$. Fifteen minutes after the injections were given, the women were asked to describe, in their own words, if they experienced any sensations, at that time point, in the injection area. All participants received an email 1 day after the procedure in which they were asked to describe if they, at that time point, had any sensations in the injection area.

\section{Ethical issues}

SWI could be experienced as painful by the women in the group not treated with EMLA ${ }^{\circledR}$. It was assumed that women with an extreme fear of needles and injections are unlikely to volunteer and so will be self-excluded from the study. Accurate information about the protocols was given to those who accepted the invitation to participate. No side effects, except for pain during injections, have earlier been reported in clinical practice. The small risk of infection was minimized via a good aseptic technique. The reason to first conduct this study with volunteers rather than women in childbirth was important. If local anesthesia with EMLA ${ }^{\circledR}$ is found to reduce the injection 
pain associated with SWI, the next step would be to investigate whether this technique also gives adequate relief of low back pain during childbirth. The participants in the present study did not receive a financial incentive. The Central Ethical Review Board in Sweden approved the study (Dnr Ö 9-2013).

\section{Analysis \\ Sample size}

Mårtensson and Wallin [20] found that female students receiving intracutaneous sterile water injections reported an average pain score of $61(\mathrm{~mm})(\mathrm{SD}=19)$ on a 100 mm VAS. Based on that study, it was estimated that the present study would require 18 subjects in each group to achieve $90 \%$ power, at a two-sided 0.001 significance level, to detect a decrease in pain of $32 \mathrm{~mm}$ (VAS). This reduction in pain may be relevant since the pain would be experienced in the range of mild to moderate pain (VAS) [39]. Including 30 patients per group (a total of 120) compensated for dropout.

\section{Statistical analysis}

The VAS score was measured in millimeters from the left anchor marked 'no pain' and the point scored by the participant [40]. Differences between the groups in demographics were tested using Fisher's Exact Test (dichotomous variables) (two and four groups), MannWhitney's test (two groups) and Kruskal-Wallis H-test (four groups) (categorical data) and t-test (two groups) and one-way ANOVA (four groups) (continuous variables). Mann-Whitney's U-test was also used to compare perceived pain (VAS scores), and within the injection area over time, between the EMLA-SWI and placebo SWI groups and between EMLA-NaCl and placebo $\mathrm{NaCl}$ group. To test differences between proportions Z-test for 2 independent proportions was also used. VAS scores are also presented as mean and standard deviation. Since the aim of this study was to evaluate the effect of topical local anesthesia on the pain associated with administration of sterile water injections, no comparisons were made between the SWI and $\mathrm{NaCl}$ groups. In keeping with the sample size calculation, a two-tailed test at the 0.001 significance level was used.

\section{Results}

A total of 120 female students participated in the study. For unknown reasons, one woman discontinued the participation. In total, 119 women were included in the analysis. The recruitment and flow chart of the study is presented in Fig. 2. There were no differences between the SWI groups or $\mathrm{NaCl}$ groups, nor between all four groups regarding socio-demographic variables (age; body

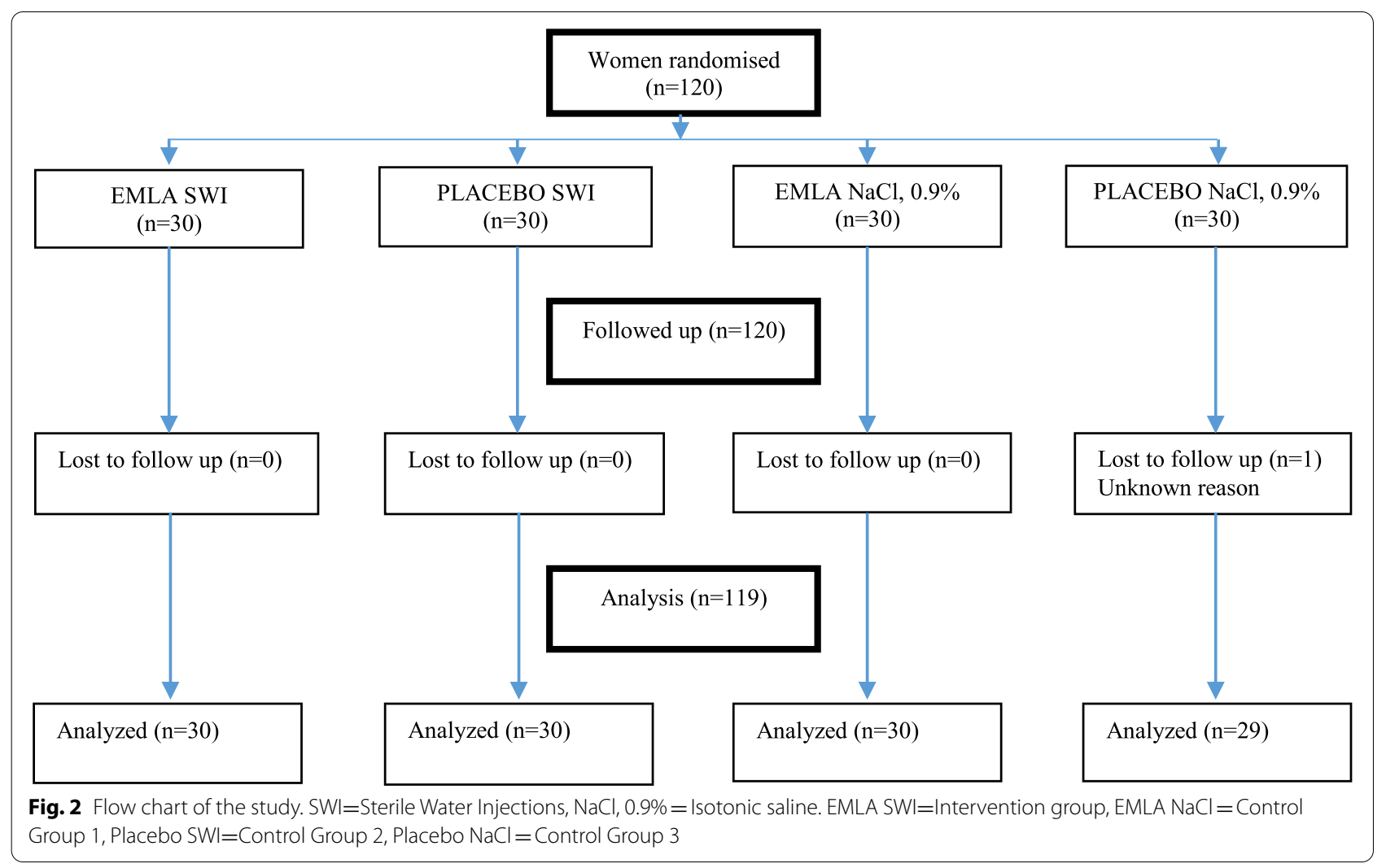


mass index; knowledge of SWI; previous childbirth; anxiety for pain and use of tobacco), Table 1.

There was a statistically significant difference regarding perceived pain of $23.3 \mathrm{~mm}$ on VAS, $1-3 \mathrm{~s}$ after the injections of sterile water were given, between the intervention group (EMLA SWI) and control group 1 (placebo SWI) (50.0 vs 73.3, $p=0.001)$. This statistically significant difference does not remain $30 \mathrm{~s}$ after the injections. However, in both groups, the perceived pain has decreased, during the time of observation, Fig. 3 and Table 2. This trend was noted in the intervention group (EMLA and SWI) but did not achieve a statistically significant difference compared to control group 1 (placebo and SWI). Further, immediately after the injections were given $(1-3 \mathrm{~s}), 30 \%(n=9)$ scored severe pain in the EMLA SWI group. The corresponding figure for the placebo SWI group was $63.3 \%(n=19),(P=0.00634)$.

After $30 \mathrm{~s}, 6.7 \%(n=2)$ in the EMLA SWI group and $20.7 \%(n=6)$ in the placebo SWI group recorded VAS equal to severe pain, $(p=0.11642)$. At $1 \mathrm{~min}$ all women, in these groups, scored their pain as mild or moderate (Fig. 3).
While at the 1-min time point, none of the women across the four groups rated their pain as severe, the range of the VAS scorings indicates a considerable individual variation in how the women perceived their pain. This was especially pronounced in the EMLA SWI group at the first time-point (1-3s after the injections).

There was also a statistically significant difference regarding perceived pain between the control group 2 (EMLA NaCl) and control group 3 (placebo) when administering injections of $\mathrm{NaCl}$. This difference remained statistically significant up to 4 min after the injections, Fig. 3 and Table 3.

In total $49 \%(n=58)$ of the participants did not report any sensations in the injection area $15 \mathrm{~min}$ after the injections were given. The remaining $51 \%(n=61)$ reported one or several sensations. Overall the most common reported sensations were sore and prickling. Sore, numb and felt warm were more frequently reported in the SWI groups compared to $\mathrm{NaCl}$ groups. Moreover, the absence of sensations was more pronounced in the $\mathrm{NaCl}$ groups compared to the SWI groups, Table 4.

To illustrate the variation of reported sensations in the four groups, some quotes are presented below.

Table 1 Participant socio-demographic variables

\begin{tabular}{|c|c|c|c|c|}
\hline & $\begin{array}{l}\text { Intervention group EMLA SWI } \\
(n=30)\end{array}$ & $\begin{array}{l}\text { Control group } 1 \\
\text { Placebo SWI }(n=30)\end{array}$ & $\begin{array}{l}\text { Control group } 2 \\
\text { EMLA NaCl }(n=30)\end{array}$ & $\begin{array}{l}\text { Control } \\
\text { group } 3 \\
\text { Placebo } \\
\mathrm{NaCl} \\
(n=30)\end{array}$ \\
\hline \multicolumn{5}{|l|}{ Age (years) } \\
\hline Mean & 27,53 & 27,30 & 26,70 & 24,70 \\
\hline $\pm S D$ & 6,01 & 6,88 & 6,48 & 4,38 \\
\hline \multicolumn{5}{|l|}{ Body mass index } \\
\hline Mean & 25,06 & 23,94 & 23,50 & 24,47 \\
\hline$+S D$ & 4,21 & 5,87 & 2,61 & 3,89 \\
\hline \multicolumn{5}{|l|}{ Knowledge ofSWI } \\
\hline Yes & 14 & 12 & 14 & 11 \\
\hline No & 16 & 18 & 16 & 18 \\
\hline \multicolumn{5}{|l|}{ Previous childbirth } \\
\hline Yes & 10 & 9 & 7 & 7 \\
\hline No & 20 & 21 & 22 & 23 \\
\hline \multicolumn{5}{|l|}{ Anxiety for pain } \\
\hline Not worried at all & 8 & 8 & 12 & 7 \\
\hline Not particularly & 20 & 20 & 16 & 19 \\
\hline worried & 2 & 1 & 2 & 3 \\
\hline Pretty worried & 0 & 1 & 0 & 0 \\
\hline \multicolumn{5}{|l|}{ Very worried } \\
\hline \multicolumn{5}{|l|}{ Use of tobacco } \\
\hline Yes & 4 & 9 & 5 & 7 \\
\hline No & 26 & 21 & 24 & 23 \\
\hline
\end{tabular}

EMLA Patch with local anesthesia, SWI Sterile water injections, $\mathrm{NaCl}$ isotonic saline $(0.9 \%)$ 


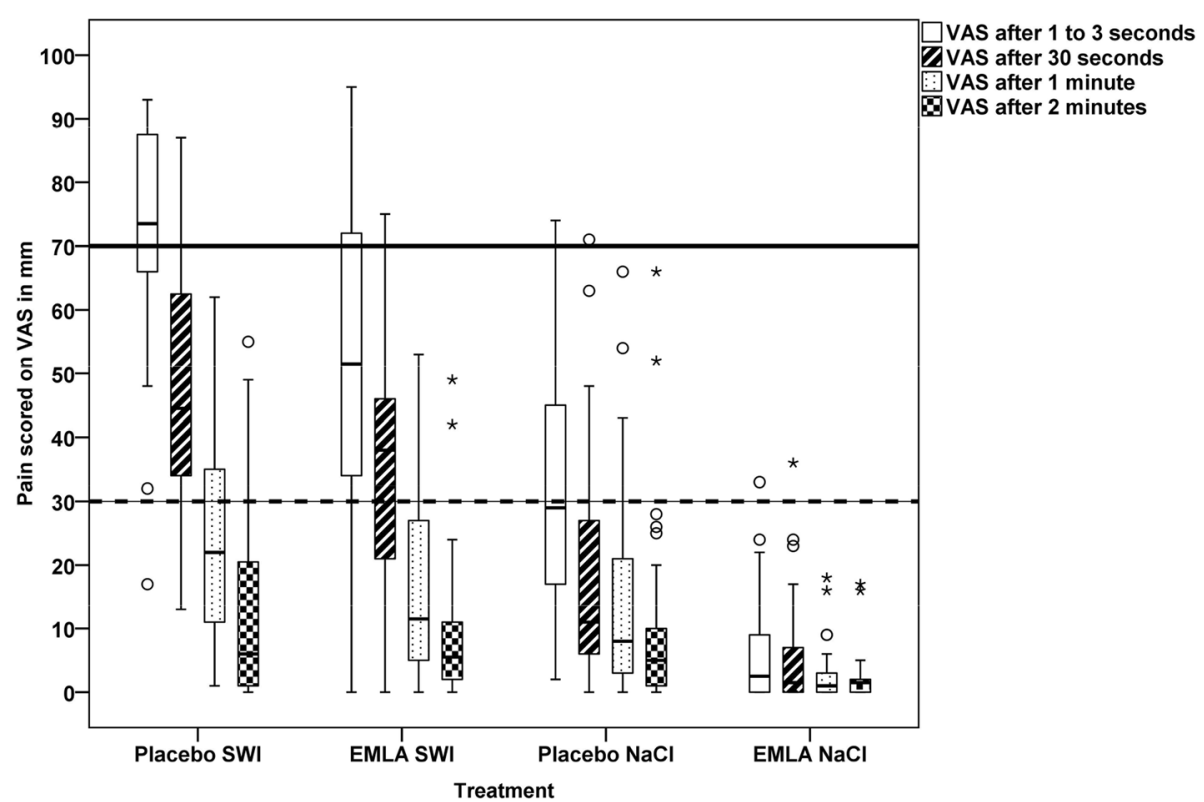

Fig. 3 Distribution of Visual Analogue Scale (VAS) scores (millimeters ( $\mathrm{mm})$ ) at the first four time-points; immediately after injection (1-3 s), $30 \mathrm{~s}, 1 \mathrm{~min}$ and $2 \mathrm{~min}$. Note, in this figure the groups are sorted after pain intensity at injection time. The cut-offs for mild $(<30 \mathrm{~mm})$, moderate $(31-70 \mathrm{~mm})$, and severe pain $(>70 \mathrm{~mm})$ is market with reference lines (y-axis)

\section{EMLA SWI}

It feels just a bit numb and somewhat warm inside, but absolutely no pain or discomfort. I felt the lower lefthand jab a bit more than the others. The whole area is generally more sensitive than my skin used to be.

It feels like I have bruises and some prickling and stinging, especially on the left side. The prickling and stinging come and go every few seconds.

\section{EMLA NaCl}

Warm feeling in the area.

Table 2 Comparison between the PLACEBO and EMLA SWI groups. VAS scores $(\mathrm{mm})$ presented as mean and standard deviation ( $(\mathrm{SD})$ at each time-point

\begin{tabular}{llll}
\hline & PLACEBO SWI & EMLA SWI & \\
\hline Time-points & Mean $( \pm$ SD $)$ & Mean $( \pm$ SD $)$ & $p$-value \\
$1-3 \mathrm{~s}$ & $73.3(18,9)$ & $50.0(26,7)$ & 0.001 \\
$30 \mathrm{~s}$ & $49.5(20,8)$ & $38.1(20,0)$ & 0.052 \\
$1 \mathrm{~min}$ & $25.3(18,0)$ & $17.1(15,3)$ & 0.056 \\
$2 \mathrm{~min}$ & $14.0(16,3)$ & $8,8(11,8)$ & 0.381 \\
$3 \mathrm{~min}$ & $8.0(12,6)$ & $3.2(5,9)$ & 0.142 \\
$4 \mathrm{~min}$ & $4.7(6,1)$ & $1.3(2,0)$ & 0.016 \\
$5 \mathrm{~min}$ & $6.5(9,0)$ & $1.7(3,5)$ & 0.003 \\
$10 \mathrm{~min}$ & $4.0(5,6)$ & $1.8(4,7)$ & 0.008 \\
$15 \mathrm{~min}$ & $3.14(6,1)$ & $1.0(2,1)$ & 0.015 \\
\hline
\end{tabular}

EMLA Patch with local anesthesia, SWI Sterile water injections
Low-grade pain. Stinging in a tennis ball-sized area on the left side. Essentially no pain at all on the right side.

\section{Placebo SWI}

I don't feel anything different at all in the area, maybe a bit warm.

Prickling, with varying intensity. Like being pinched or extreme numbness at the site of injection. It's not exactly painful but more of a stinging sensation in the spots where I was jabbed.

Table 3 Comparison between the PLACEBO and EMLA NaCl groups. VAS scores $(\mathrm{mm})$ presented as mean and standard deviation ( $(\mathrm{SD})$ at each time-point

\begin{tabular}{llll}
\hline & PLACEBO NaCl & EMLA NaCl & \\
\hline Time-points & Mean $( \pm$ SD $)$ & Mean $( \pm S D)$ & p-value \\
$1-3 \mathrm{~s}$ & $34.0(21,7)$ & $6.0(8,5)$ & 0.000 \\
$30 \mathrm{~s}$ & $18.6(19,0)$ & $6.0(8,9)$ & 0.000 \\
$1 \mathrm{~min}$ & $14.0(16,7)$ & $2.8(4,6)$ & 0.000 \\
$2 \mathrm{~min}$ & $10.6(15,8)$ & $2.4(4,1)$ & 0.008 \\
$3 \mathrm{~min}$ & $6.17(8,3)$ & $1.8(3,3)$ & 0.005 \\
$4 \mathrm{~min}$ & $3.8(5,0)$ & $1.3(2,1)$ & 0.028 \\
5 min & $2.0(2,5)$ & $1.3(2,1)$ & 0.116 \\
$10 \mathrm{~min}$ & $1.3(1,8)$ & $1.8(3,4)$ & 0.916 \\
15 min & $1.4(1,8)$ & $2.5(7,3)$ & 0.236 \\
\hline EMLA Patch with local anesthesia, NaCl Isotonic saline $(0.9 \%)$ &
\end{tabular}

EMLA Patch with local anesthesia, $\mathrm{NaCl}$ Isotonic saline (0.9\%) 
Table 4 Sensations reported 15 min after injections were given. In total 119 women responded to this question. Some women have reported more than one sensation

\begin{tabular}{|c|c|c|c|c|}
\hline Sensation & $\begin{array}{l}\text { PLACEBO } \\
\text { and SWI }\end{array}$ & EMLA and SWI & $\begin{array}{l}\text { PLACEBO } \\
\text { and } \mathrm{NaCl}\end{array}$ & $\begin{array}{l}\text { EMLA and } \\
\mathrm{NaCl}\end{array}$ \\
\hline Sore & 9 & 5 & & 1 \\
\hline Prickling & 7 & 2 & 5 & 1 \\
\hline Stinging & 6 & 3 & 4 & 2 \\
\hline Felt warm & 4 & 4 & 1 & 1 \\
\hline Numb & 4 & 4 & 1 & \\
\hline Grinding ache & 4 & 2 & 1 & 1 \\
\hline Swollen & 2 & 1 & & \\
\hline Throbbing & 2 & & & \\
\hline Unpleasant & 1 & 1 & 1 & 1 \\
\hline Stiff & & 3 & 1 & 1 \\
\hline Pleasant & & 1 & & \\
\hline Total & 39 & 26 & 14 & 8 \\
\hline $\begin{array}{l}\text { Reported no } \\
\text { particular } \\
\text { sensation }\end{array}$ & 9 & 10 & 17 & 22 \\
\hline
\end{tabular}

EMLA Patch with local anesthesia, SWI Sterile water injections, $\mathrm{NaCl}$ isotonic saline $(0.9 \%)$

\section{Placebo $\mathrm{NaCl}$ \\ I don't feel anything, either where I got the jab or in area around it.}

Prickling every now and then, mostly on the left. Sometimes the prickling is quite painful, but in between, I don't feel any pain at all.

The day after the experiment, four women reported some sensations in the injection area. In the intervention group (EMLA SWI) discomforting $(n=1)$ and sore $(\mathrm{n}=1)$, in control group 1 (placebo SWI) sore $(\mathrm{n}=1)$ and in control group 2 (EMLA $\mathrm{NaCl})$ stiff $(n=1)$. No sensations were reported in control group 3 (placebo $\mathrm{NaCl}$ ). No other adverse side effects were reported.

\section{Discussion}

The main finding in this study was that local anesthesia with EMLA ${ }^{\circledR}$ reduces the perceived pain when administering intracutaneous (also called intradermal) injections of sterile water. Immediately after the injections were given, $70 \%$ scored mild or moderate pain (EMLA SWI group) the corresponding figure for the placebo SWI group was $37 \%$. Our findings suggest that the use of EMLA may make the injection pain of SWI more tolerable for women.

This is the first study to report the pain and other sensations related to the injections beyond the initial treatment. At $15 \mathrm{~min}$ post-injection the most common reported sensations were sore, numb and felt warm. These were more frequently reported in the SWI groups compared to $\mathrm{NaCl}$ groups. Moreover, the absence of sensations was more pronounced in the $\mathrm{NaCl}$ groups compared to the SWI groups. The reason for this is unknown. However, it is relevant to assume that this has to do with the fact that sterile water is salt-free which could induce an osmotic gradient in the skin as previously described [41].

Despite that SWI has been proven to be a highly effective pain relief method, without any adverse side effects $[4,7]$, some women are doubtful of the method. Earlier it has been reported that some women rated the injection pain as more painful than the contraction pain [10] with a self-reported VAS of $90-100 \mathrm{~mm}$ [14]. The reduction of perceived pain related to the injections in the present study may mean that laboring women are more likely to use this pain relief method. Furthermore, it has been reported that midwives find it counter-intuitive to cause women additional pain when using SWI to relieve childbirth pain [11]. However, it may be more likely that midwives would recommend SWI if using an EMLA patch before treatment.

As this study aimed to establish if the use of topical anesthetic creams could reduce the pain of SWI and non-pregnant women were included as participants, there remain two essential questions that this trial was not designed to address. Firstly, as the EMLA cream takes 60-90 min to achieve an effect, would this delay in providing analgesia be acceptable to women? A woman in childbirth would, not unsurprisingly, want pain relief directly after providing her informed decision about the analgesic method for her labor pain. The delay in the effect of the EMLA and similar topical anesthetics could be too long to wait for the woman. An alternative may be to apply the EMLA patches early if the woman considers SWI a treatment for back pain, as the patches can be left in place for up to $5 \mathrm{~h}$. Secondly, would the reduction in injection pain negatively impact the resulting analgesia? No studies have directly explored the relationship between injection pain and the degree of resulting analgesia. Previous studies have determined that single water injection is given at the point on the back where the woman perceives her pain to be most substantial results in a significant pain reduction $[12,13]$. However, the pain of the injection was not reported. One trial compared a single to four injections and found that the single injection was significantly less painful than four and resulted in a significantly reduced analgesic effect [14]. However, women were still quite satisfied with the analgesia provided by the one injection. This suggests there may be a tradeoff between a more acceptable level of pain and a reduced but still effective degree of analgesia. 
It is essential, for several reasons, to develop safe and effective non-pharmacological pain relief methods offered to women during childbirth. Many women wish to avoid methods that use drugs because of known or unknown side effects for the mother and the unborn baby. It is also essential to identify techniques that provide minimal side effects and discomfort with the highest possible pain relief. SWI has been shown to provide adequate relief of back pain in labor, however, the associated injection pain acts as a deterrent to widespread use. As the study was conducted on non-pregnant women, it is not known if reducing the injection pain will impact the degree or duration of analgesia usually associated with SWI. The next step is, therefore, to evaluate if the pain relief effect for childbirth back pain remains after local anesthesia of the skin before treatment with intracutaneous sterile water injections. The method might also be an option for women in parts of the world where there is limited access to pain relief methods during childbirth. The reduction in injection pain found in this trial may increase the utility of SWI as an option for other severe pain conditions such as ureterolithiasis or other different kinds of chronic pain.

\section{Strength and limitations}

The study had several strengths. The trial was conducted according to a registered protocol, and only one woman discontinued participation. A number of control groups were used to explore the various combinations of EMLA versus $\mathrm{SWI}$ and $\mathrm{NaCl}$. Limitations of the study involve the inability to blind the administration of the EMLA and placebo patches and the water and $\mathrm{NaCl}$ injections. The participants were unaware of the group to which they were randomized. However, there is a distinct difference regarding the pain experience between the injections of sterile water versus $\mathrm{NaCl}$, which could have alerted the women of group allocation.

\section{Conclusion}

The present study suggests that the use of topical anesthetic creams at least $1 \mathrm{~h}$ prior to the administration of SWI does reduce the injection pain experienced. However, the time taken for the anesthetic to take effect may prove impractical for some women or require some planning earlier in labor.

\section{Abbreviations}

$\mathrm{NaCl}$ : Isotonic saline 0.9\%; SWI: Sterile Water Injections; VAS: Visual Analogue Scale.

\section{Acknowledgements}

The authors would like to thank the students who participated in the study for their generous contribution of time and effort.

\section{Authors' contributions}

LBM, NL and IB conceptualized the study. BMG, SK, LBM and IB managed the data collection. $L B M, B M G$, SK and IB analyzed the data. $L B M, B M G, N L$ and IB drafted the manuscript. All authors have reviewed and approved the final manuscript.

\section{Funding}

Open access funding provided by University of Skövde. Financial support for the study was provided by the University of Skövde, the School of Health Sciences, the research environment Digital Health Research (DHEAR) and the research group Family-Centered Health (FamCeH).

\section{Availability of data and materials}

The datasets generated during and or analyzed during the current study are available from the corresponding author on reasonable request.

\section{Declarations}

\section{Ethics approval and consent to participate}

A description of ethics approval and consent to participate is presented under the headline Ethical issues in the manuscript. The Central Ethical Review Board in Sweden approved the study (Dnr Ö 9-2013). All methods were performed in accordance with relevant guidelines and regulations. Prior to the data collection the participants were given written and orally information about the study. Informed consent was obtained from all participants before the study was started.

\section{Consent for publication}

Consent for publication was obtained from the person in Fig. 1 Locations of the injections.

\section{Competing interests \\ The authors declare that they have no competing interests.}

\section{Author details}

${ }^{1}$ School of Health Sciences, University of Skövde, P.O. Box 408, SE-541 28 Skövde, Sweden. ${ }^{2}$ School of Nursing, Midwifery and Social Work University of Queensland, Chamberlain Building, University of Queensland," St Lucia, Queensland 4072, Australia. ${ }^{3}$ School of Health and Welfare, Jönköping University, P.O. Box 1026, SE-551 11 Jönköping, Sweden.

Received: 15 October 2021 Accepted: 10 January 2022

Published online: 01 February 2022

\section{References}

1. Waldenstrom $U$, Schytt E. A longitudinal study of women's memory of labour pain--from 2 months to 5 years after the birth. BJOG. 2009;116(4):577-83.

2. Garthus-Niegel S, Knoph C, von Soest T, Nielsen CS, Eberhard-Gran M. The role of labor pain and overall birth experience in the development of posttraumatic stress symptoms: a longitudinal cohort study. Birth Berkeley, Calif. 2014;41(1):108-15.

3. Enkin K, Keirse MJNC, Neilson J, Crowther C, Duley L, Hednett E, et al. A guide to effective care in pregnancy and childbirth. 3rd ed. New York: Oxford University Press; 2000. p. 525.

4. Martensson LB, Hutton EK, Lee N, Kildea S, Gao Y, Bergh I. Sterile water injections for childbirth pain: an evidenced based guide to practice. Women Birth. 2018;31(5):380-5.

5. Ahmadnia $\mathrm{H}$, Younesi RM. Treatment of renal colic using intracutaneous injection of sterile water. Urol J. 2004;1(3):200-3.

6. Xue P, Tu C, Wang K, Wang X, Fang Y. Intracutaneous sterile water injection versus oral paracetamol for renal colic during pregnancy: a randomized controlled trial. Int Urol Nephrol. 2013;45(2):321-5.

7. Lee N, Gao Y, Collins SL, Martensson LB, Randall W, Rowe TM, et al. Caesarean delivery rates and analgesia effectiveness following injections of sterile water for back pain in labour: a multicentre, randomised placebo controlled trial. EClinicalMedicine. 2020;25:100447. 
8. Fogarty $V$. Intradermal sterile water injections for the relief of low back pain in labour -- a systematic review of the literature. Women Birth. 2008;21(4):157-63.

9. Martensson L, Wallin G. Sterile water injections as treatment for low-back pain during labour: a review. Aust N Z J Obstet Gynaecol. 2008;48(4):369-74.

10. Lee N, Kildea S, Stapleton H. "no pain, no gain": the experience of women using sterile water injections. Women Birth. 2017;30(2):153-8.

11. Lee N, Kildea S, Stapleton H. 'Tough love': the experiences of midwives giving women sterile water injections for the relief of back pain in labour. Midwifery. 2017;53:80-6.

12. Bahasadri S, Ahmadi-Abhari S, Dehghani-Nik M, Habibi GR. Subcutaneous sterile water injection for labour pain: a randomised controlled trial. Aust N Z J Obstet Gynaecol. 2006;46(2):102-6.

13. Kushtagi P, Bhanu BT. Effectiveness of subcutaneous injection of sterile water to the lower back for pain relief in labor. Acta Obstet Gynecol Scand. 2009;88(2):231-3.

14. Lee N, Webster J, Beckmann M, Gibbons K, Smith T, Stapleton H, et al. Comparison of a single vs. a four intradermal sterile water injection for relief of lower back pain for women in labour: a randomised controlled trial. Midwifery. 2013;29(6):585-91.

15. Mårtensson L. Sterile water injections for labour pain. Licentiate's dissertation. Göteborg:: Göteborg University; 2003.

16. Simkin PP, O'Hara M. Nonpharmacologic relief of pain during labor: systematic reviews of five methods. Am J Obstet Gynecol. 2002;186(5 Suppl Nature):S131-59.

17. Hutton EK, Kasperink M, Rutten M, Reitsma A, Wainman B. Sterile water injection for labour pain: a systematic review and meta-analysis of randomised controlled trials. BJOG. 2009;116(9):1158-66.

18. Martensson L. The patient observer: sterile water injections for labor pain. Birth Berkeley, Calif. 2010;37(4):334-6.

19. Mårtensson L, Nyberg K, Wallin G. Subcutaneous versus intracutaneous injections of sterile water for labour analgesia: a comparison of perceived pain during administration. BJOG. 2000;107(10):1248-51.

20. Martensson L, Wallin G. Labour pain treated with cutaneous injections of sterile water: a randomised controlled trial. Br J Obstet Gynaecol. 1999;106(7):633-7.

21. Byrn C, Olsson I, Falkheden L, Lindh M, Hosterey U, Fogelberg M, et al. Subcutaneous sterile water injections for chronic neck and shoulder pain following whiplash injuries. Lancet. 1993;341(8843):449-52.

22. Iwama H, Ohmori S, Kaneko T, Watanabe K. Water-diluted local anesthetic for trigger-point injection in chronic myofascial pain syndrome: evaluation of types of local anesthetic and concentrations in water. Reg Anesth Pain Med. 2001;26(4):333-6.

23. Melzack R, Wall PD. Pain mechanisms: a new theory. Science. 1965;150(699):971-9.

24. Olausson $H$, Lamarre $Y$, Backlund $H$, Morin C, Wallin BG, Starck G, et al. Unmyelinated tactile afferents signal touch and project to insular cortex. Nat Neurosci. 2002;5(9):900-4

25. Le Bars D, Dickenson AH, Besson JM. Diffuse noxious inhibitory controls (DNIC). I. Effects on dorsal horn convergent neurones in the rat. Pain. 1979;6(3):283-304.

26. Shrestha P, Stoeber B. Fluid absorption by skin tissue during intradermal injections through hollow microneedles. Sci Rep. 2018;8(1):13749.

27. Schulz KF, Altman DG, Moher D, Group C. CONSORT 2010 statement: updated guidelines for reporting parallel group randomised trials. J Clin Epidemiol. 2010;63(8):834-40.

28. Fillingim RB. Sex, gender, and pain. In: Legato M, editor. Principles of gender-specific medicine. 3rd ed: Academic Press; 2017. p. 481-96.

29. Moore DJ, Keogh E, Eccleston C. Identifying experimental methods to determine the effect of pain on attention: a review of pain, caffeine, alcohol and nicotine studies. Hum Psychopharmacol. 2009;24(8):601-18.

30. Packiasabapathy S, Sadhasivam S. Gender, genetics, and analgesia: understanding the differences in response to pain relief. J Pain Res. 2018;11:2729-39.

31. FASS. (Farmaceutiska specialiteter i Sverige) Pharmaceutical specialties in Sweden. 2020.

32. Wahlgren $\mathrm{CF}$, Quiding $\mathrm{H}$. Depth of cutaneous analgesia after application of a eutectic mixture of the local anesthetics lidocaine and prilocaine (EMLA cream). J Am Acad Dermatol. 2000;42(4):584-8.
33. Visual HE, Scales A. In: Melzack R (ed) pain measurement and assesment. New York: Raven; 1983. p. 293.

34. Joyce CR, Zutshi DW, Hrubes V, Mason RM. Comparison of fixed interval and visual analogue scales for rating chronic pain. Eur J Clin Pharmacol. 1975:8(6):415-20

35. Choiniere M, Melzack R, Girard N, Rondeau J, Paquin MJ. Comparisons between patients' and nurses' assessment of pain and medication efficacy in severe burn injuries. Pain. 1990;40(2):143-52.

36. Herr KA, Spratt K, Mobily PR, Richardson G. Pain intensity assessment in older adults: use of experimental pain to compare psychometric properties and usability of selected pain scales with younger adults. Clin J Pain. 2004;20(4):207-19.

37. Jensen MP, Karoly P, Braver S. The measurement of clinical pain intensity: a comparison of six methods. Pain. 1986;27(1):117-26.

38. Bodian CA, Freedman G, Hossain S, Eisenkraft JB, Beilin Y. The visual analog scale for pain: clinical significance in postoperative patients. Anesthesiology. 2001;95(6):1356-61.

39. Collins SL, Moore RA, McQuay HJ. The visual analogue pain intensity scale: what is moderate pain in millimetres? Pain. 1997;72(1-2):95-7.

40. Todd KH. Pain assessment instruments for use in the emergency department. Emerg Med Clin North Am. 2005;23(2):285-95.

41. Lindahl O. Experimental skin pain induced by injection of water-soluble substances in humas. [Dissertation] Stockholm: Karolinska Institutet; 1961.

\section{Publisher's Note}

Springer Nature remains neutral with regard to jurisdictional claims in published maps and institutional affiliations.
Ready to submit your research? Choose BMC and benefit from:

- fast, convenient online submission

- thorough peer review by experienced researchers in your field

- rapid publication on acceptance

- support for research data, including large and complex data types

- gold Open Access which fosters wider collaboration and increased citations

- maximum visibility for your research: over $100 \mathrm{M}$ website views per year

At BMC, research is always in progress.

Learn more biomedcentral.com/submissions 